Case Reports in
Gastroenterology
Case Rep Gastroenterol 2021;15:35-40

DOI: 10.1159/000509950

Published online: January 21, 2021

(c) 2021 The Author(s)

OPEN

Published by S. Karger AG, Basel ACCESS

This article is licensed under the Creative Commons Attribution-NonCommercial 4.0 International License (CC BY-NC) (http://www.karger.com/Services/OpenAccessLicense). Usage and distribution for commercial purposes requires written permission.

\title{
Case of Incarcerated Femoral Hernia Treated with Laparoscopic Surgery after Groin Hernia Repair
}

\author{
Yuki Tsuchiya Hirotaka Momose Kazumasa Kure Hisashi Ro \\ Rina Takahashi Yu Okazawa Masaya Kawai Makoto Takahashi \\ Yutaka Kojima Kazuhiro Sakamoto \\ Department of Coloproctological Surgery, Juntendo University Faculty of Medicine, \\ Tokyo, Japan
}

\section{Keywords}

Groin hernia $\cdot$ Incarcerated femoral hernia $\cdot$ Laparoscopic surgery

\begin{abstract}
An 81-year-old man was brought to our hospital due to a suspicion of left incarcerated femoral hernia. He was previously diagnosed with incarcerated left groin hernia and was treated using the mesh plug method 1 month back at another hospital. Abdominal computed tomography scan revealed small bowel obstruction, incarcerated bowel, and compression of the left femoral vein. Thus, the patient was diagnosed with incarcerated femoral hernia. An emergency laparoscopic surgery was then performed, and we found that the small bowel was incarcerated into the let femoral ring and was necrotic. However, there was no recurrence of left inguinal hernia. The small necrotic bowel was resected and the femoral ring was repaired. The patient was discharged 8 days after the surgery, and there was no recurrence of femoral hernia after 1 year.
\end{abstract}




\section{Case Reports in Gastroenterology}

\begin{tabular}{l|l}
\hline Case Rep Gastroenterol 2021:15:35-40 \\
\hline DOI: 10.1159/000509950 & $\begin{array}{l}\text { ○ 2021 The Author(s). Published by S. Karger AG, Basel } \\
\text { www.karger.com/crg }\end{array}$ \\
\hline
\end{tabular}

Tsuchiya et al:: Case of Incarcerated Femoral Hernia Treated with Laparoscopic Surgery after Groin Hernia Repair

\section{Introduction}

Although femoral hernia is less common than inguinal hernia, it is often associated with incarceration and causes significant morbidity and mortality. The femoral ring is bound laterally by the femoral vein, anteriorly by the inguinal ligament, medially by the lacunar ligament, and posteriorly by the pectineal ligament. Femoral hernia must be treated immediately after diagnosis due to the high incidence of strangulation [1]. Herein, we report a rare case of incarcerated femoral hernia treated with laparoscopic surgery after groin hernia repair in a Japanese male patient.

\section{Case Presentation}

An 81-year-old man presented with left groin pain for 1 month, and he was previously diagnosed with incarcerated left groin hernia 1 month back at another hospital. The hernia was repaired using ProLoopTM (L) Mesh Plug. He was referred to our institution due to left femoral swelling and pain lasting for $9 \mathrm{~h}$. He was $155 \mathrm{~cm}$ tall and weighed $50 \mathrm{~kg}$ (body mass index of 20.8). Physical examination revealed left femoral tenderness below the surgical scar (Fig. 1). However, the patient did not complain of abdominal pain and rebound tenderness. The femoral hernia cannot be repaired. The laboratory examination findings were normal. Abdominal radiography revealed no gas fluid and signs of small bowel dilatation. Abdominal computed tomography scan showed a small round mass compressing the left femoral vein and small bowel obstruction (Fig. 2a, b). Based on these findings, a preoperative diagnosis of incarcerated femoral hernia was made, and emergency surgery was performed.

Laparoscopic small bowel resection and femoral ring repair were conducted under general anesthesia. The patient was in supine position, and the three-port method was used. Three operation ports were established, which were as follows: a 12-mm umbilical camera port and 5-mm working ports in the lower right and left flank area. We found that the small bowel was incarcerated into the left femoral ring. However, there was no recurrence of left groin hernia (Fig. 3a). The left inguinal ligament was amputated, thereby loosening the formal ring. A hernia was found, and a surface area of $4 \mathrm{~cm}$ in the small bowel was dark red (Fig. 3b). To reduce the risk of infection, small bowel resection was performed after closing the femoral ring. The diameter of the femoral ring was $1 \mathrm{~cm}$, and it was washed and closed with a oneneedle suture (Fig. 3c). The umbilical port was extended by $3 \mathrm{~cm}$, and the small bowel was resected via a functional end-to-end anastomosis. The patient had an uneventful postoperative course and was discharged 8 days after the surgery. There was no recurrence of femoral hernia after 1 year.

\section{Discussion}

The incidence rate of femoral hernia is approximately 2-8\% in adults [2]. Femoral hernia is more common in women than in men, with a female-to-male ratio of $4: 1$, because of the wider structure of the pelvis [3]. Femoral hernias account for about $2-4 \%$ of all groin hernias [4]. Approximately $60 \%$ of femoral hernias are found on the right side, $30 \%$ on the left side, and $10 \%$ bilaterally [5].

\section{Karger'=}




\section{Case Reports in Gastroenterology}

Case Rep Gastroenterol 2021;15:35-40

DOI: 10.1159/000509950

(c) 2021 The Author(s). Published by S. Karger AG, Basel www.karger.com/crg

Tsuchiya et al.: Case of Incarcerated Femoral Hernia Treated with Laparoscopic Surgery after Groin Hernia Repair

A femoral hernia is more common on the right side than on the left side, as in this case, probably due to the anatomical position of the sigmoid colon. The bowel may tampon the femoral canal [6]. The incarceration/strangulation rate of femoral hernia was between $44 \%$ and 86\% [7]. In this case, intraperitoneal assessment revealed that the mesh plug method could be used to repair the femoral ring. When using this method in an incarcerated case, the mesh including the femoral ring must be repaired. Regarding the method applied in repairing a femoral hernia in case of bowel resection, it is common not to use artificial materials, such as those utilized in McVay repair. This method is often used in emergency surgery, and some surgeons have never used it. Surgeons find it challenging to understand the anatomy of femoral hernias after groin hernia because of the effects of surgery. By contrast, the use of a laparoscope can facilitate the direct assessment of an incarcerated bowel, and the viability of the bowel can be evaluated. In addition, the condition could be treated with transabdominal preperitoneal repair.

Based on the guidelines of the World Society of Emergency Surgery, patients with a complex hernia with intestinal strangulation and/or concomitant need for bowel resection without gross enteric spillage (clean-contaminated surgical field, Centers for Disease Control and Prevention [CDC] wound class II) can undergo emergent prosthetic repair with a synthetic mesh (without any increase in 30-day wound-related morbidity), and this procedure is associated with a significantly lower risk of recurrence, regardless of the hernia defect size (grade $1 \mathrm{~A}$ recommendation) [8]. For stable patients with strangulated hernia with bowel necrosis and/or gross enteric spillage during intestinal resection (contaminated surgical field, CDC wound class III) or peritonitis from bowel perforation (dirty surgical field, CDC wound class IV), primary repair is recommended when the defect is $<3 \mathrm{~cm}$. However, when direct suturing is not feasible, a biological mesh may be used for repair. In our case, small bowel necrosis was observed. However, there was no abscess formation or perforation. Thus, the wound was classified as CDC wound class II. Hence, mesh repair could be performed. The use of a mesh in femoral hernia repair might cause infection of the groin hernia mesh or improper fixation. The size of the femoral ring was as small as $1 \mathrm{~cm}$. Thus, a simple closure method was used. In fact, no study has performed laparoscopic mesh repair of a femoral hernia after groin hernia using the mesh plug method. Based on a recent study, two-stage laparoscopic treatment was considered safe for the treatment of strangulated inguinal, femoral, and obturator hernias, and complete mesh repair using the TEP method can be performed in elderly patients to minimize the occurrence of mesh infection [9]. However, in femoral hernia after groin hernia surgery, the mesh must be removed, and a new mesh is re-inserted. Hence, laparoscopic femoral ring closure, which is a minimally invasive and effective surgical procedure, was considered. Data about the use of a laparoscopic approach for cases of incarcerated femoral hernia are limited. Thus, more data on such cases must be collected.

In conclusion, laparoscopic surgery is considered effective for the treatment of femoral hernia, particularly that occurring after groin hernia.

\section{Acknowledgements}

We would like to thank Eloise for revising this article, including English expressions.

\section{Karger'"}




\section{Case Reports in Gastroenterology}

\begin{tabular}{l|l}
\hline Case Rep Gastroenterol 2021:15:35-40 \\
\hline DOI: 10.1159/000509950 & $\begin{array}{l}\text { ○ 2021 The Author(s). Published by S. Karger AG, Basel } \\
\text { www.karger.com/crg }\end{array}$ \\
\hline
\end{tabular}

Tsuchiya et al.: Case of Incarcerated Femoral Hernia Treated with Laparoscopic Surgery after Groin Hernia Repair

\section{Statement of Ethics}

This study was performed in accordance with the ethical standards of the Committee on Human Experimentation of our institution. Patient consent was obtained for describing his clinical course in a case report.

\section{Conflict of Interest Statement}

The authors declare no conflict of interest. The authors declare that they have no competing interests.

\section{Funding Sources}

The authors declare that this work was not supported by any grants or funding.

\section{Author Contributions}

Data acquisition (Y.T., H.M., K.K., H.R., R.T., Y.O., M.K.). Drafting of the manuscript (Y.T.). Critical revision of the manuscript (Y.T., M.T., Y.K., K.S.).

\section{References}

1 Gallegos NC, Dawson J, Jarvis M, Hobsley M. Risk of strangulation in groin hernias. Br J Surg. 1991 Oct;78(10):1171-3.

2 Hachisuka T. Femoral hernia repair. Surg Clin North Am. 2003 Oct;83(5):1189-205.

3 Pillay Y. Laparoscopic repair of an incarcerated femoral hernia. Int J Surg Case Rep. 2015;17:85-8.

4 Bay-Nielsen M, Kehlet H, Strand L, Malmstrøm J, Andersen FH, Wara P, et al.; Danish Hernia Database Collaboration. Quality assessment of 26,304 herniorrhaphies in Denmark: a prospective nationwide study. Lancet. 2001 Oct;358(9288):1124-8.

5 Franklin ME Jr, Gonzalez JJ Jr, Michaelson RP, Glass JL, Chock DA. Preliminary experience with new bioactive prosthetic material for repair of hernias in infected fields. Hernia. 2002 Dec;6(4):171-4.

6 Hernandez-Richter T, Schardey HM, Rau HG, Schildberg FW, Meyer G. The femoral hernia: an ideal approach for the transabdominal preperitoneal technique (TAPP). Surg Endosc. 2000 Aug;14(8):736-40.

7 Oishi SN, Page CP, Schwesinger WH. Complicated presentations of groin hernias. Am J Surg. 1991 Dec;162(6):568-70.

8 Birindelli A, Sartelli M, Di Saverio S, Coccolini F, Ansaloni L, van Ramshorst GH, et al. 2017 update of the WSES guidelines for emergency repair of complicated abdominal wall hernias. World J Emerg Surg. 2017 Aug;12(1):37.

9 Sasaki A, Takeuchi Y, Izumi K, Morimoto A, Inomata M, Kitano S. Two-stage laparoscopic treatment for strangulated inguinal, femoral and obturator hernias: totally extraperitoneal repair followed by intestinal resection assisted by intraperitoneal laparoscopic exploration. Hernia. 2016 Jun;20(3):483-8. 
Case Reports in Gastroenterology
Case Rep Gastroenterol 2021;15:35-40

DOI: 10.1159/000509950

(c) 2021 The Author(s). Published by S. Karger AG, Basel www.karger.com/crg

Tsuchiya et al:: Case of Incarcerated Femoral Hernia Treated with Laparoscopic Surgery after Groin Hernia Repair

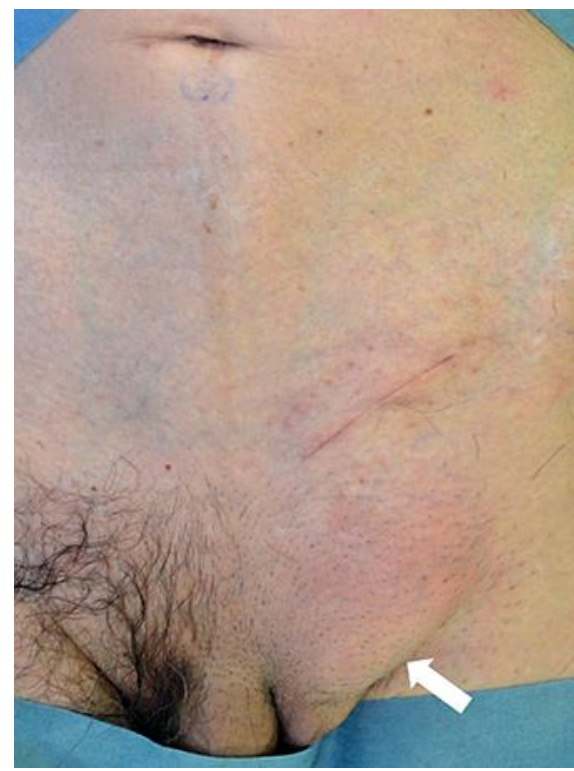

Fig. 1. A bulge was observed on the left femoral area below the groin hernia surgical scar.
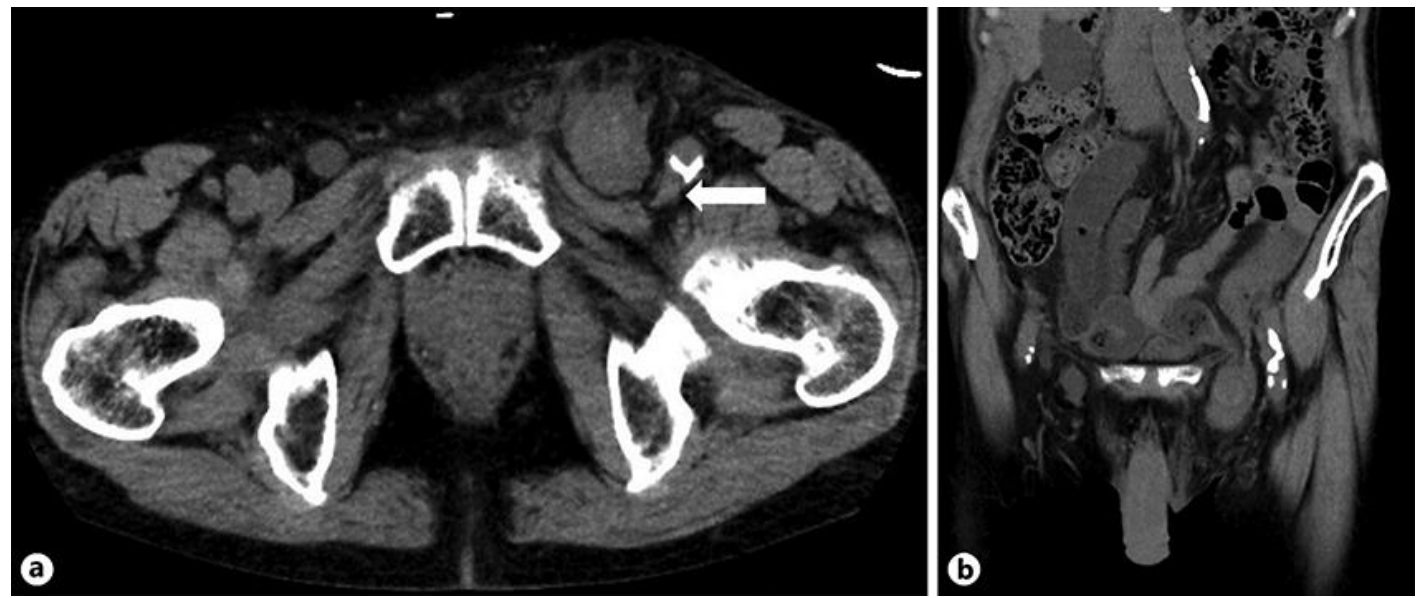

Fig. 2. a Computed tomography scan revealed that the small bowel compressed the left femoral vein (arrow). b Moreover, small bowel obstruction was observed, and incarcerated bowel was suspected. 
Case Reports in Gastroenterology
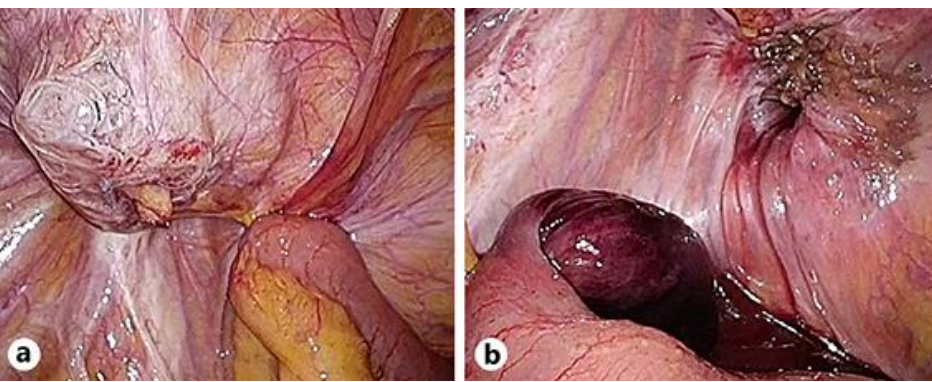

Fig. 3. a Laparoscopy revealed that the small bowel was incarcerated into the left femoral ring. However, there was no recurrence of left inguinal hernia. $\mathbf{b}$ The small bowel was incarcerated and was partially necrotic. $\mathbf{c}$ The femoral ring was repaired via suturing. 